Pacific Journal of Mathematic 


\section{ON ASYMPTOTIC ESTIMATES FOR KERNELS OF CONVOLUTION TRANSFORMS}

\section{Zeev Ditzian}

In this paper we shall try to answer two open questions posed by Dauns and Widder in their paper "Convolution transforms whose inversion functions have complex roots" (Pacific Journal of Mathematics, 1965, Volume 15(2), pp. 427-442) on page 441.

We shall be interested in the function $G_{2 m}(t)$ defined by

$$
G_{2 m}(t)=\frac{1}{2 \pi i} \int_{-i \infty}^{i \infty} \frac{e^{s t} d s}{E_{2 m}(s)}
$$

where

$$
E_{2 m}(s)=\prod_{k=m+1}^{\infty}\left(1-\frac{s^{2}}{a_{k}^{2}}\right)
$$

where $\left\{a_{k}\right\}$ is a sequence of complex numbers such that

$$
\left|\arg a_{k}\right|<\frac{\pi}{4}-\eta
$$

for a fixed $\eta, 0<\eta<\pi / 4$,

$$
\sum_{k}^{\infty}\left|a_{k}\right|^{-2}<\infty, \quad 0<\operatorname{Re} a_{i} \leqq \operatorname{Re} a_{i+1} \text { for all } i
$$

and

$$
\lim _{m \rightarrow \infty}\left|a_{m+1}\right|^{2} \sum_{k=m+1}^{\infty}\left|a_{k}\right|^{-2}=\infty .
$$

If a sequence $\left\{a_{k}\right\}$ satisfies all the above assumptions, we shall denote it by $\left\{a_{k}\right\} \in \operatorname{class} C$. We obtain condition $B$, defined in $[1, \mathrm{p}$. $436]$, if we replace (1.3) by (1.4)

$$
\lim _{n \rightarrow \infty}\left|a_{n+1}\right|^{4 / 3} \sum_{n+1}^{\infty}\left|a_{k}\right|^{-2}=\infty \text {. }
$$

If we take $a_{k}=k^{\lambda} 1 / 2<\lambda<\infty$ then $\left\{a_{k}\right\} \in \operatorname{class} C$, but of these sequences only those for which $1 / 2<\lambda<3 / 2$ satisfy condition $B$.

We define as in [1]

$$
V_{m}=\sum_{k=m+1}^{\infty} a_{k}^{-2} \text { and } S_{m}=\sum_{k=m+1}^{\infty}\left|a_{k}\right|^{-2}
$$


and whenever $\left\{a_{k}\right\} \in$ class $C$ we prove

$$
\lim _{m \rightarrow \infty} \int_{-\infty}^{\infty}\left|t G_{2 m}^{\prime}(t)\right| d t=\left(\cos ^{2} \varphi_{m}-\sin ^{2} \varphi_{m}\right)^{-3 / 2}
$$

where

$$
\varphi_{m}=\frac{1}{2} \arg V_{m}\left(-\frac{\pi}{2}<\arg V_{m}<\frac{\pi}{2}\right)
$$

which answers the question posed in remark (3) [1, p. 441].

We shall also prove under the restriction $\left\{a_{k}\right\} \in$ class $C$ Corollary 4.3 and an analogous theorem to Theorem 4.1.

As a by product we shall have

$$
\lim _{m \rightarrow \infty} S_{m}^{1 / 2} \frac{d^{n}}{d t^{n}} G_{2 m}\left(S_{m}^{1 / 2} t\right)=\frac{1}{\sqrt{4 \pi}}\left(\frac{S_{m}}{V_{m}}\right)^{1 / 2} \frac{d^{n}}{d t^{n}} \exp \left(-t^{2} \frac{S_{m}}{4 V_{m}}\right)
$$

which is more than necessary for proving other results and is an interesting estimate of $G_{2 m}^{(n)}(t)$ by itself.

2. Some lemmas. In the author's thesis [2] and in a paper in collaboration with A. Jakimovski [3; Lemma 2.1.] the following lemma. was proved:

Lemma 2.1. Suppose $\sum_{k_{k=1}^{\infty}}^{\infty}\left|a_{k}\right|^{-2}<\infty$ then the assumptions

$$
\sum_{k=m+1}^{\infty}\left|a_{k}\right|^{-(2+\alpha)}=o\left(\left(\sum_{k=m+1}^{\infty}\left|a_{k}\right|^{-2}\right)^{1+(\alpha / 2)}\right) \quad m \rightarrow \infty
$$

for some fixed $\alpha>0$ and

$$
\lim _{m \rightarrow \infty}\left(\max _{k>m}\left|a_{k}\right|^{-2}\right)\left(\sum_{k=m+1}^{\infty}\left|a_{k}\right|^{-2}\right)^{-1}=0
$$

are equivalent, and therefore the assumptions (2.1) for all positive $\alpha$ are equivalent.

Proof. Let us assume (2.1) for some $\alpha>0$. If (2.3) is not valid then a subsequence $\{m(r)\}$ of $m+1, m+2, \cdots$ exists such that for some $\beta>0$

$$
\left(\max _{k \geqq m(r)+1}\left|a_{k}\right|^{-2}\right) S_{m(r)}^{-1} \geqq \beta>0
$$

for all $r \geqq 1$. Therefore

$$
\sum_{k=m(r)+1}^{\infty}\left|a_{k}\right|^{-\Omega-\alpha} \geqq\left(\max _{k \geqq m(r)+1}\left|a_{k}\right|^{-2}\right)^{1+(\alpha / 2)} \geqq \beta^{1+(\alpha / 2)} S_{m(r)}^{1+(\alpha / 2)}
$$

which contradicts (2.1). 
Assuming (2.2) then

$$
\begin{aligned}
& \sum_{k=m+1}^{\infty}\left|a_{k}\right|^{-2-\alpha}=\sum_{k=m+1}^{\infty}\left|a_{k}\right|^{-2} \leqq\left(\max _{k \geqq m+1}\left|a_{k}\right|^{-\alpha}\right) S_{m} \\
& =\left(\left(\max _{k \geq m+1}\left|a_{k}\right|^{-2}\right) S_{m}^{-1}\right)^{\alpha / 2} S_{m}^{1+(\alpha / 2)} \\
& =o\left(S_{m}^{1+(\alpha / 2)}\right) \\
& (m \rightarrow \infty) \text {. }
\end{aligned}
$$

The following two lemmas are easy to verify.

Lemma 2.2. If $\left\{a_{k}\right\} \in \operatorname{class} C$ then $\left\{a_{k}\right\}$ satisfies assumption (2.2). If $\left|\arg a_{k}\right|<\pi / 4-\eta, 0<\operatorname{Re} a_{i} \leqq \operatorname{Re} a_{i+1}$ and $\left\{a_{k}\right\}$ satisfies assumption (2.2) then $\left\{a_{k}\right\} \in \operatorname{class} C$.

Lemma 2.3. If $\left|\arg a_{k}\right|<(\pi / 4)-\eta$ and $\sum\left|a_{k}\right|^{-2}<\infty$, then

$$
\cos \left(\frac{\pi}{2}-2 \eta\right) S_{n} \leqq\left|V_{n}\right| \leqq S_{n}
$$

We define now $F_{n}(z)$ by

$$
F_{m}(z)=E_{m}\left(z \cdot S_{m}^{-1 / 2}\right)=\sum_{k=m+1}^{\infty}\left(1-\frac{z^{2}}{a_{k}^{2} S_{m}}\right) .
$$

Lemma 2.4. Suppose $\left\{a_{k}\right\} \in \operatorname{class} C$ then there exist constants $k(p)>0$ independent of $m$ so that for all real $y$

$$
\left|F_{m}(i y)\right|>1+k(p) y^{o p} \quad \text { for } m>m_{0}(p) \text {. }
$$

Proof. Define $a_{k}=\left|a_{k}\right| e^{i \beta_{k}},-(\pi / 4)+\eta<\beta_{k}<(\pi / 4)-\eta$

$$
\begin{aligned}
\left|F_{m}(i y)\right| & =\left|\prod_{k=m+1}^{\infty}\left(1-\frac{(i y)^{2}}{a_{k}^{2} S_{m}}\right)\right| \\
& \geqq \prod_{k=m+1}^{\infty}\left(1+\frac{y^{2}}{\left|a_{k}\right|^{2} S_{m}} \cos 2 \beta_{k}\right) \\
& \geqq \prod_{k=m+1}^{\infty}\left(1+\frac{y^{2} \cos \left(\frac{\pi}{2}-2 \eta\right)}{\left|a_{k}\right|^{2} S_{m}}\right) \\
& =1+\sum_{p=1}^{\infty} \frac{y^{2 p} \cos ^{p}\left(\frac{\pi}{2}-2 \eta\right)}{S_{m}^{p} p !} \sum_{\substack{i \neq j \\
i \neq j(i)>m b(j) \neq k(j)}}\left|a_{k(1)} \cdots a_{k(p)}\right|^{-2} .
\end{aligned}
$$

Since we have $\lim _{m \rightarrow \infty} \max _{k>m}\left|a_{k}\right|^{-2} S_{m}^{-1}=0$ we can find $m_{0}(p)$ so that for $m>m_{0}(p) \max _{k>m}\left|a_{k}^{-2}\right|<(1 / 2 p) S_{m}$. Therefore we have 


$$
\begin{aligned}
& \sum_{\substack{k(i)>m \\
k(i) \neq k(j), i \neq j}}\left|a_{k(1)} \cdots a_{k(p)}\right|^{-2} \\
& =\sum_{\substack{k(i)>m \\
k(i) \neq k(j), i \neq j}}\left(S_{m}-\sum_{i=1}^{p-1}\left|a_{k(i)}\right|^{-2}\right)\left|a_{k(1)} \cdots a_{k(p-1)}\right|^{-2} \\
& \geqq \frac{1}{2} S_{m} \sum_{\substack{k(i)>m \\
k(i) \neq k(j), j \neq i}}\left|a_{k(1)} \cdots a_{k(p-1)}\right|^{-2} \geqq\left(\frac{1}{2}\right)^{p} S_{m}^{p} .
\end{aligned}
$$

Hence

$$
\left|F_{m}(i y)\right| \geqq 1+y^{2 p} \frac{\cos ^{p}\left(\frac{\pi}{2}-2 \eta\right) S_{m}^{p}}{S_{m}^{p} p ! 2^{p}}=1+k(p) y^{2 p} .
$$

3. The asymptotic estimates for $G_{2 m}^{(k)}(t)$.

Theorem 3.1. Let $\left\{a_{k}\right\} \in$ clase $C$; then for all $n=0,1, \ldots$

(3.1) $\lim _{m \rightarrow \infty} S_{m}^{1 / 2} \frac{d^{n}}{d t^{n}} G_{2 m}\left(S_{m}^{1 / 2} t\right)=\frac{1}{\sqrt{4 \pi}}\left(\frac{S_{m}}{V_{m}}\right)^{1 / 2} \frac{d^{n}}{d t^{n}} \exp \left(-t^{2} \frac{S_{m}}{4 V_{m}}\right)$

uniformly in $-\infty<t<\infty$ (we choose $\left.\arg V_{m}^{1 / 2}=(1 / 2) \arg V_{m}\right)$.

Proof. Following the proof of the special case $n=0$ and arg; $a_{k}=0$ by Hirschman-Widder [4; pp. 140-1] we have

$$
S_{m}^{1 / 2} G_{2 m}\left(S_{m}^{1 / 2} t\right)=\frac{1}{2 \pi i} \int_{-i \infty}^{i \infty} \frac{e^{z t} d z}{F_{2 m}(s)}=\frac{1}{2 \pi} \int_{-\infty}^{\infty} \frac{e^{i y t} d y}{F_{2 m}(i y)} .
$$

By an estimate of $[5 ; \mathrm{p} .246]$ we have for $|z|<R$ and

$$
\begin{gathered}
R \cdot\left[\left|a_{k}\right| S_{m}^{1 / 2}\right]^{-1} \leqq \frac{1}{2} \\
\left|\log \left\{\left(1-\frac{z^{2}}{a_{k}^{2} S_{m}}\right) \exp \left(z^{2} / a_{k}^{2} S_{m}\right)\right\}\right| \leqq 4 R^{3} \frac{1}{\left|a_{k}\right|^{3} S_{m}^{3 / 2}} .
\end{gathered}
$$

Recalling that $\sum_{k=m+1}^{\infty} 1 / a_{k}^{2} S_{m}=V_{m} / S_{m}$ and since by Lemma 2.1

$$
\sum_{k=m+1}^{\infty} \frac{1}{\left|a_{k}\right|^{3} S_{m}^{3 / 2}}=o(1) m \rightarrow \infty,
$$

we have for $|z|<R$ and $m>m_{0}(R)$

$$
\left|F_{m}(z)-\exp \left(-\frac{V_{m} z^{2}}{S_{m}}\right)\right|<\varepsilon_{1} .
$$

Since by Lemma $2.4 R>R_{0}\left(\varepsilon_{2}, \eta\right)$ implies

$$
\int_{R}^{\infty} \frac{|y|^{n} d y}{\left|F_{2 m}(i y)\right|}<\varepsilon_{2} \text { and } \int_{-\infty}^{-R} \frac{|y|^{n} d y}{\left|F_{2 m}(i y)\right|}<\varepsilon_{2}
$$


we have

$$
\begin{aligned}
S_{m}^{1 / 2} \frac{d^{n}}{d t^{n}} G_{2 m}\left(S_{m}^{1 / 2} t\right) \\
=\frac{1}{2 \pi} \int_{-\infty}^{\infty} \frac{(i y)^{n} e^{i y t}}{F_{m}(i y)} d y \\
=\frac{1}{2 \pi} \int_{-\infty}^{\infty}(i y)^{n} \exp \left(-\frac{V_{m}}{S_{m}} y^{2}+i y t\right) d y+o(1) \\
=\frac{d^{n}}{d t^{n}}\left\{\exp \left(-\frac{t^{2} S_{m}}{4 V_{m}}\right)\right. \\
\left.\quad \times \frac{1}{2 \pi} \int_{-\infty}^{\infty} \exp \left[-\left(V_{m}^{1 / 2} S_{m}^{-1 / 2} y-i t S_{m}^{1 / 2}\left(4 V_{m}\right)^{-1 / 2}\right)^{2}\right] d y\right\}+o(1) \\
=\left(\frac{S_{m}}{V_{m}}\right)^{1 / 2} \frac{d^{n}}{d t^{n}}\left\{\exp \left(-\frac{t^{2} S_{m}}{4 V_{m}}\right) \frac{1}{2 \pi} \int_{\Gamma} e^{-z^{2}} d z\right\}+o(1) \\
=\frac{1}{\sqrt{4 \pi}}\left(\frac{S_{m}}{V_{m}}\right)^{1 / 2} \frac{d^{n}}{d t^{n}} \exp \left(\frac{-t^{2} S_{m}}{4 V_{m}}\right)+o(1)
\end{aligned}
$$

using the residue theorem, the fact that $e^{-z^{2}}$ is entire and that

$$
\left|\arg V_{m}^{1 / 2}\right|<\frac{\pi}{4} \quad \text { for all } m
$$

As a corollary we derive

THEOREM 3.2. If $\left\{a_{k}\right\}$ satisfies assumption $C$ then

$$
\int_{-\infty}^{\infty}\left|G_{2 m}(t)\right| d t=\left(\cos ^{2} \varphi_{m}-\sin ^{2} \varphi_{m}\right)^{-1 / 2}+o(1) \quad m \rightarrow \infty
$$

and

$$
\int_{-\infty}^{\infty}\left|t G_{2 m}^{\prime}(t)\right| d t=\left(\cos ^{2} \varphi_{m}-\sin ^{2} \varphi_{m}\right)^{-3 / 2}+o(1) \quad m \rightarrow \infty
$$

where $2 \varphi_{m}=\arg V_{m}$.

Proof. Since by Lemma 2.4 of [1].

$$
\left|G_{2 m}(t)\right|<M S_{m}^{-1 / 2} \exp \left(-K S_{m}^{-1 / 2}|t|\right)
$$

we have

$$
\begin{aligned}
& \int_{-\infty}^{\infty}\left|G_{2 m}(t)\right| d t=\int_{-\infty}^{\infty}\left|S_{m}^{1 / 2} G_{2 m}\left(S_{m}^{1 / 2} t\right)\right| d t=\int_{-R}^{R}\left|S_{m}^{1 / 2} G_{2 m}\left(S_{m}^{1 / 2} t\right)\right| d t \\
& \quad+o(1) \quad(R \uparrow \infty) .
\end{aligned}
$$

This combined with (3.1) and a simple integration yield (3.2).

To prove (3.3) we use Lemma 3.2 case $A$ (since for $\left\{a_{k}\right\} \in$ class $C$ $S_{m} \geqq 4 r_{m+1}^{-2} \equiv 4\left|a_{m+1}\right|^{-2}$ for $m>m_{0}$ ) which is 


$$
\left|G_{2 m}^{\prime}(t)\right| \leqq M_{1} S_{m}^{-1} \exp \left(-K_{1} S_{m}^{-1 / 2}|t|\right) .
$$

Therefore we have

$$
\int_{R}^{\infty}\left|S_{m} t G_{2 m}^{\prime}\left(S_{m}^{1 / 2}|t|\right)\right| d t \leqq M_{1} \frac{1}{\left(K_{1}\right)^{2}} e^{-K_{1} R}=o(1) \quad R \rightarrow \infty
$$

This implies

$$
\begin{aligned}
& \int_{-\infty}^{\infty}\left|t G_{2 m}^{\prime}(t)\right| d t=\int_{-\infty}^{\infty}\left|S_{m} t G_{2 m}^{\prime}\left(S_{m}^{1 / 2} t\right)\right| d t \\
& \quad=\frac{1}{2 \sqrt{4 \pi}}\left|\frac{S_{m}}{V_{m}}\right|^{3 / 2} \int_{-\infty}^{\infty} t^{2} \exp \left(-\frac{t^{2}}{4} S_{m} \operatorname{Re} \frac{1}{V_{m}}\right) d t+o(1) \\
& \quad=\left(\frac{\left|V_{m}\right|^{-1}}{\left(\operatorname{Re}\left(V_{m}^{-1}\right)\right)}\right)^{3 / 2}+o(1)=\left(\cos ^{2} \varphi_{m}-\sin ^{2} \varphi_{m}\right)^{-3 / 2}+o(1) \quad(m \uparrow \infty) .
\end{aligned}
$$

4. Remarks. I. For the theorems and the lemmas proved in this paper $0<\operatorname{Re} a_{i} \leqq \operatorname{Re} a_{i+1}$ is not essential and the condition (2.2) can replace it and (1.3).

II. Theorem 3.1 which replaces Theorem 4.1 yields for the case $n=0$ only the following

$$
G_{2 m}(t)=\left(4 \pi V_{m}\right)^{-1 / 2} \exp \left(-t^{2} / 4 V_{m}\right)+o\left(S_{m}^{-1 / 2}\right) \quad m \rightarrow \infty
$$

but if one follows the proof of Theorem 4.1 of [1] and Lemma 4.2 of [1] almost litarally one obtains for $\left\{a_{k}\right\} \in$ class $C$

$$
G_{2 m}(t)=\left(4 \pi V_{m}\right)^{-1 / 2} \exp \left(-t^{2} / 4 V_{m}\right)+o\left(\left|a_{m+1}\right|^{-2} S_{m}^{-3 / 2}\right) \quad m \rightarrow \infty
$$

which is somewhat more general.

\section{REFERENCES}

1. J. Dauns and D. V. Widder, Convolution transforms whose inversion function have complex roots, Pacific J. Math. (2) 15 (1965).

2. Z. Ditzian, Inversion formulae and various properties of integral transforms (Thesis, 1965, Hebrew University).

3. Z. Ditzian and A, Jakimovski, Inversion and Jump formulae for convolution transform (to appear).

4. I. I. Hirschman and D. V. Widder, The Convolution Transform, Princeton Press, 1955.

5. E. C. Titchmarsh, The Theory of Functions, Oxford University Press, 1932.

Received May 23, 1966.

WASHINGTON UNIVERSITY

ST. Louis, Missouri and

Michigan State UNIVERSity

East Lansing, Michigan 


\section{PACIFIC JOURNAL OF MATHEMATICS}

\section{EDITORS}

H. SAMELSON

Stanford University

Stanford, California

J. P. JANS

University of Washington

Seattle, Washington 98105

\section{J. DugunduI}

University of Southern California Los Angeles, California 90007

RICHARD ARENS

University of California

Los Angeles, California 90024

\section{ASSOCIATE EDITORS}
E. F. BECKENBACH
B. H. NEUMANN
F. WOLF
K. YoSIDA

\section{SUPPORTING INSTITUTIONS}

\author{
UNIVERSITY OF BRITISH COLUMRIA \\ CALIFORNIA INSTITUTE OF TECHNOLOGY \\ UNIVERSITY OF CALIFORNIA \\ MONTANA STATE UNIVERSITY \\ UNIVERSITY OF NEVADA \\ NEW MEXICO STATE UNIVERSITY \\ OREGON STATE UNIVERSITY \\ UNIVERSITY OF OREGON \\ OSAKA UNIVERSITY \\ UNIVERSITY OF SOUTHERN CALIFORNIA
}

\author{
STANFORD UNIVERSITY \\ UNIVERSITY OF TOKYO \\ UNIVERSITY OF UTAH \\ WASHINGTON STATE UNIVERSITY \\ UNIVERSITY OF WASHINGTON \\ AMERICAN MATHEMATICAL SOCIETY \\ CHEVRON RESEARCH CORPORATION \\ TRW SYSTEMS \\ NAVAL ORDNANCE TEST STATION
}

Mathematical papers intended for publication in the Pacific Journal of Mathematics should be typewritten (double spaced). The first paragraph or two must be capable of being used separately as a synopsis of the entire paper. It should not contain references to the bibliography. Manuscripts may be sent to any one of the four editors. All other communications to the editors should be addressed to the managing editor, Richard Arens at the University of California, Los Angeles, California 90024 .

50 reprints per author of each article are furnished free of charge; additional copies may be obtained at cost in multiples of 50 .

The Pacific Journal of Mathematics is published monthly. Effective with Volume 16 the price per volume (3 numbers) is $\$ 8.00$; single issues, $\$ 3.00$. Special price for current issues to individual faculty members of supporting institutions and to individual members of the American Mathematical Society: $\$ 4.00$ per volume; single issues $\$ 1.50$. Back numbers are available.

Subscriptions, orders for back numbers, and changes of address should be sent to Pacific Journal of Mathematics, 103 Highland Boulevard, Berkeley 8, California.

Printed at Kokusai Bunken Insatsusha (International Academic Printing Co., Ltd.), No. 6, 2-chome, Fujimi-cho, Chiyoda-ku, Tokyo, Japan.

\section{PUBLISHED BY PACIFIC JOURNAL OF MATHEMATICS, A NON-PROFIT CORPORATION}

The Supporting Institutions listed above contribute to the cost of publication of this Journal, but they are not owners or publishers and have no responsibility for its content or policies. 


\section{Pacific Journal of Mathematics}

\section{Vol. 21, No. 2 December, 1967}

Arne P. Baartz, The measure algebra of a locally compact semigroup ..... 199

Robert F. Brown, On maps with identical fixed point sets............. 215

C. Buttin, Existence of a homotopy operator for Spencer's sequence in the analytic case ..................................... 219

Henry Werner Davis, An elementary proof that Haar measurable almost periodic functions are continuous ........................ 241

Zeev Ditzian, On asymptotic estimates for kernels of convolution transforms ...................................... 249

Robert E. Edwards, Boundedness principles and Fourier theory ......... 255

John A. Hildebrant, On compact unithetic semigroups ............... 265

Marinus A. Kaashoek and David Clark Lay, On operators whose Fredholm set is the complex plane ............................ 275

Sadao Kató, Canonical domains in several complex variables ........... 279

David Clifford Kay, The ptolemaic inequality in Hilbert geometries.... . . . 293

Joseph D. E. Konhauser, Biorthogonal polynomials suggested by the Laguerre polynomials ............................. 303

Kevin Mor McCrimmon, Macdonald's theorem with inverses .......... 315

Harry Eldon Pickett, Homomorphisms and subalgebras of multialgebras .................................... 327

Richard Dennis Sinkhorn and Paul Joseph Knopp, Concerning nonnegative matrices and doubly stochastic matrices ..............

Erling Stormer, On anti-automorphisms of von Neumann algebras ...

Miyuki Yamada, Regular semi-groups whose idempotents satisfy permutation identities .......................... 